\title{
Effect of water column, sediment and time over the tidal cycle on the chemical composition of tidal water in a mesohaline marsh*
}

\author{
Thomas G. Wolaver** and Joseph Zieman \\ Department of Environmental Sciences, University of Virginia, Charlottesville, Virginia 22903, USA
}

\begin{abstract}
A detailed nutrient exchange study, supported by experimental chamber work, indicates that location on the marsh, depth within the water column, and time over the tidal cycle all affect the chemical composition of tidal water which inundates the marsh surface. On the flood tide, over the low marsh (tall Spartina alterniflora), ammonia and orthophosphate apparently are released into the water column and taken up by the sediment, while on the high marsh (medium $S$. alterniflora) these constituents are removed from the tidal water the year round. Later in the tidal cycle these nutrients are released from low marsh sediments and removed from the water column. This implies ammonium and orthophosphate are tightly cycled within the vegetated marsh system. Nitrite and nitrate are always removed from the tidal water, except during fall when a large release of nitrite into the tidal water was observed. There is evidence to suggest that when the water volume to sediment surface area is small, nitrite and nitrate are used by the sediment whereas later in the tidal cycle near high tide most of the available $\mathrm{NO}_{2}^{-1}$ and $\mathrm{NO}_{3}{ }^{-1}$ is used within the water column. DON and DOP are both released and taken up from the tidal water over the low marsh depending on season of the year and whether it is a flood or ebb tide while these nutrients are always removed from the tidal water over the high marsh. Most of the particulate nitrogen and phosphorus was removed over the low marsh on the flood tide.
\end{abstract}

\section{INTRODUCTION}

Many of the biological and chemical processes which potentially control the exchange of nitrogen and phosphorus within the sediment and the water column of a vegetated marsh have been described. This work includes field studies performed on specific subsystems within the marsh complex and the adjacent estuary (Pomeroy, 1963; Pomeroy et al., 1965; Ustach, 1969; Reimold, 1972; Armentano and Woodwell, 1975; Gardner, 1975; Whitney et al., 1975; Heywood, 1977; Sherr and Payne, 1977; Kaplan et al., 1979) and speculations derived from nutrient exchange studies conducted in tidal creeks (Axelrad, 1974; Heinle and Flemer, 1976; Woodwell and Whitney, 1977 ; Valiela et al., 1978).

Pomeroy et al. (1965) and Patrick and Khalid (1974) found that the sediment system may control the orthophosphate concentration in the overlying water of

\footnotetext{
- This study was supported by Seagrant \# R/ER-1

- Present address: Belle W. Baruch Institute for Marine Biology and Coastal Research, University of South Carolina, PO Box 1630, Georgetown, SC 29440, USA
}

estuaries via clay sorption of this constituent onto clay particles, while release of $\mathrm{PO}_{4}{ }^{-3}$ occurs when the dissolved concentration is low. This process may explain the phosphorus dynamics in the Flax Pond nutrient exchange study (Woodwell and Whitney, 1977). Releases of $\mathrm{PO}_{4}{ }^{-3}$ from the sediment system via diffusion into tidal pools during low tide exposure was studied by Gardner (1975), while short term turnover of $\mathrm{p}^{32}$ through biological organisms in the water column has been observed by Pomeroy (1963). The plant system with its associated detritus has also been shown to be important in orthophosphate dynamics since Reimold (1972) showed that Spartina alterniflora released $\mathrm{PO}_{4}^{-3}$ into water via plant guttation, and utilization of orthophosphate by bacteria decomposing S. alterniflora detritus was observed by Ustach (1969) and Heywood (1977).

Gardner (1975) hypothesized that ammonium will diffuse into tidal water left on the marsh during tidal exposure, this material being transported into the estuary via drainage. Some of this ammonium may be produced by nitrogen fixation (Whitney et al., 1975; Hanson, $1977 \mathrm{a}, \mathrm{b})$ which has been shown to occur in 
both the high and low marsh sediments. Ammonium is lost from the water column by either uptake via floating organisms or utilization by microbes decomposing nitrogen deficient detritus laying on the marsh surface (Ustach, 1969; Heywood, 1977). Nitrite is usually only present in very small quantities in salt water marshes. This constituent is used as a nutrient for biological organisms and may serve as an electron acceptor in the denitrification process. Aurand and Daiber (1973) qualitatively determined that a vegetated marsh removed nitrate from tidal water; this was later supported by Axelrad (1974). This constituent is also used as a nutrient and as an electron acceptor in the denitrification process.

There have been only a few studies which specifically address the problem of what controls the concentration of dissolved organics and particulates in tidal water (Stephens, 1963, 1964, 1967; Armentano and Woodwell, 1975; Gleason et al., 1979). Axelrad (1974) has hypothesized that dissolved organic phosphorus and nitrogen may be released into the inundating water via invertebrate excretion, while Stephens $(1963,1964,1967)$ has shown that organics in general are utilized by various organisms as a nutrient source. Armentano and Woodwell (1975) indicated that the deposition rate of particulate material is greater on the low marsh than on the high marsh in the Flax Pond system, due to the effects of increased tidal inundation. This is supported by the lab experiments of Gleason et al. (1979) which showed that Spartina alterniflora stems act as a sediment trap, deposition rates increasing when tidal water first interacts with the marsh vegetation.

A detailed nutrient exchange study was conducted on a vegetated marsh in the Carters Creek area of Virginia, in order to study how the processes described above may control the nutrient composition of tidal water inundating a mesohaline marsh (see also Wolaver, 1982a, b). By using this approach, coupled with in situ chamber experiments, an assessment can be made of (1) whether the sediment substrate or the water column is responsible for the processing of nutrients in the tidal water as a function of location on the marsh and time over the tidal cycle and (2) which physical, chemical or biological processes may be responsible for the observed nutrient exchange.

\section{METHODS}

This research was conducted on the Carter Creek marsh area adjoining the York River, $10 \mathrm{~km}$ northwest of Gloucester Point, Virginia (Fig. 1). This is a mesohaline (6 to $20 \%$ S) marsh covered by tall and medium Spartina alterniflora. In this paper the tall $S$.

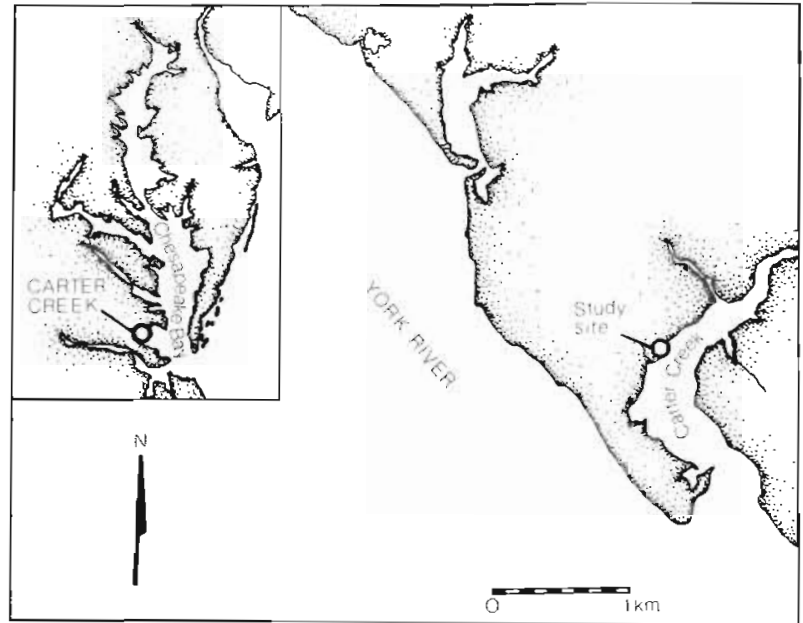

Fig. 1. Site map

alterniflora zone is referred to as low marsh, and the medium $S$. alterniflora zone is called high marsh. The site was selected because of the shallow elevation gradient across the marsh surface. This allows tidal water to move onto the marsh in a uniform manner, lateral flow being minimal. To insure that there was no lateral movement of tidal water, Plexiglas fencing was used to form a flume $1.8 \mathrm{~m}$ wide and $23 \mathrm{~m}$ long. This structure was aligned perpendicular to the marsh creek.

Water samples for nutrient analyses were collected at $1 / 2$ to $1 \mathrm{~h}$ intervals over a tidal cycle at 2 locations on the marsh surface. One sample site was situated at the creek bank edge of the $S$. alterniflora marsh (Station A), the second was at the interface between the tall and medium S. alterniflora zone (Station B). To quantify the depth profile of nutrients, 4 samples were taken at the Station $\mathrm{A}(0,10 \mathrm{~cm}, 25 \mathrm{~cm}$ and $45 \mathrm{~cm}$ above the sediment), and 3 samples $(0,10 \mathrm{~cm}$, and $25 \mathrm{~cm}$ above the sediment) at Station $B$, depending on the height of water in the flume. Each water sample was split in the field; one part was left unfiltered while the other was inline-filtered with a Gelman glass fiber filtering apparatus. Both samples were frozen immediately in a dry ice-acetone bath and stored for later analysis. The nitrogen and phosphorus species analyzed for include: $\mathrm{NH}_{4}{ }^{+1}, \mathrm{NO}_{3}{ }^{-1}, \mathrm{NO}_{2}^{-1}$, dissolved organic nitrogen $(\mathrm{DON})$, particulate nitrogen (PN), $\mathrm{PO}_{4}^{-3}$, dissolved organic phosphorus (DOP), and particulate phosphorus (PP). The chemical techniques used in this study are discussed in earlier publications (Wolaver et al., 1983a, b). This procedure was repeated every 2 wk from January 1978 through January 1979, and once a month from January to October 1979. A total of 34 tidal cycles were sampled during both day and night time periods.

To obtain nutrient exchange as a function of location on the marsh (high and low marsh), depth within the 
water column, and time over the tidal cycle, the nutrient data must be combined with the appropriate tidal discharge information. The water discharge through the flume was estimated by subtracting the volume of tidal water in the flume at time $t+1$ from the volume at time $t$. The amount of water within the flume at time $t$ was determined from the height of water over the marsh and topographic data collected from within the flume. The discharge calculations were made every 15 min throughout the tidal cycle at each of the sampling stations.

By computer analysis discharge data can be reduced in such a way that parcels of water can be followed as they traverse the marsh surface. Dye studies indicated that intact parcels of water do in fact move on to and off the marsh on the flood and ebb tide. For each sampling date the parcel of water studied was defined as the volume of water that floods the high marsh. This volume of water was analyzed for changes in nutrient concentration as it traversed the low marsh on the flood tide (flood parcel), flooded the high marsh (high marsh parcel), and then receded back across the low marsh (ebb parcel). The remaining tidal water which floods the low marsh but never enters the high marsh zone, was called the innertide parcel. This analysis allows for a determination of nutrient exchange as a function of parcel type (flood, high marsh, ebb, and innertide). The dissolved organic and particulate nitrogen and phosphorus data were analyzed via this procedure. The results are presented as the average amount of material removed or released into the various water parcels per tidal cycle on a volumetric basis $\left(\mu \mathrm{g} \mathrm{l}^{-1}\right.$ ). The data were divided into 2 time periods, June 15 to September 16 (period s), and October 1 to June 1 (period $w$ ).

Since the nutrient data for the dissolved inorganic nitrogen and phosphorus species was collected at 4 depths at Station $A$ and at 3 depths at Station B, an assessment of nutrient exchange as a function of water column depth can also be made. A computer program was designed to divide the flux of nutrients in the tidal water into 2 depth zones. Depth 1 is 0 to $5 \mathrm{~cm}$ above the bottom, and Depth 2, the rest of the water column. For this analysis the tidal water was divided into the 4 previously described parcels. In addition the data was divided temporally into the 2 time periods presented above ( $w$ and $s$ ). This analysis allows for a determination of the nutrient exchange as a function of depth in the water column, location on the marsh, time over the tidal cycle, and season. This data is also expressed on a volumetric basis $\left(\mu \mathrm{g} \mathrm{l}^{-1}\right)$. A computer program (MANOVA) was used to determine if there is a significant difference between the means of nutrient exchange as a function of depth and parcel.

Field chamber experiments were conducted in the high and low marsh in order to determine how the water column and sediment subsystems processed ammonium, nitrite, nitrate, and orthophosphate. The experimental chambers were constructed from 6 inch diameter Plexiglas tubing cut into 4 foot lengths. The chamber design allows flooding water to enter at the sediment water interface through a single inlet and exit the same route on the ebb tide. Water samples were removed from the experimental chambers from this inlet every one-half hour during the tidal cycle. These samples were analyzed for the dissolved inorganic nitrogen and phosphorus species. Chambers used to determine sediment exchange were open at the bottom so water flooding the chamber contacted the marsh sediments. The control chambers were identical in design except that a Plexiglas plate was attached to the bottom to prevent contact with the sediment. The flux of nutrients into and out of the water within the chambers was determined by coupling the nutrient concentration with the discharge of water into and out of the chambers. The latter was determined from the height of water in the chamber over the tidal cycle. Sediment exchange was determined by subtracting the nutrient exchange results of the control chambers (water column events) from those of the sediment chambers (water column and sediment events).

\section{RESULTS}

The nutrient exchange data (Fig. 2a, b) indicates that within Depth 1 ( 0 to $5 \mathrm{~cm}$ above sediment) there is an uptake of ammonium within the flood and high marsh parcels and a release of this constituent into the ebb parcel, and innertide parcel (Depth 1) regardless of season. The general trend for the water column (Depth 2) is a release of ammonium into the tidal water early in the tidal cycle (flood parcel) and a removal of this constituent during the rest of the tidal regime. Orthophosphate is removed from the tidal water next to the sediment (Depth 1) early in the tidal cycle and later released into the ebb parcel (Depth 1, Fig. 2c, d). Regardless of season, this constituent is removed from the innertide parcel (Depth 1). Within the water column (Depth 2, summer) the general trend is release of $\mathrm{PO}_{4}^{-3}$ into the flood parcel and a removal of this constituent from the high marsh, ebb, and innertide parcels. During the winter orthophosphate is removed from the water column (Depth 2) of all the tidal parcels.

The nutrient exchange data for nitrite is broken into 3 time periods: winter (November 1 to June 1), summer (June 15 to August 17), and fall (August 17 to October 18). The levels of nitrite activity as a function of depth within the tidal water are generally very low during the winter and summer (Fig. 3a, b) and indicate a 

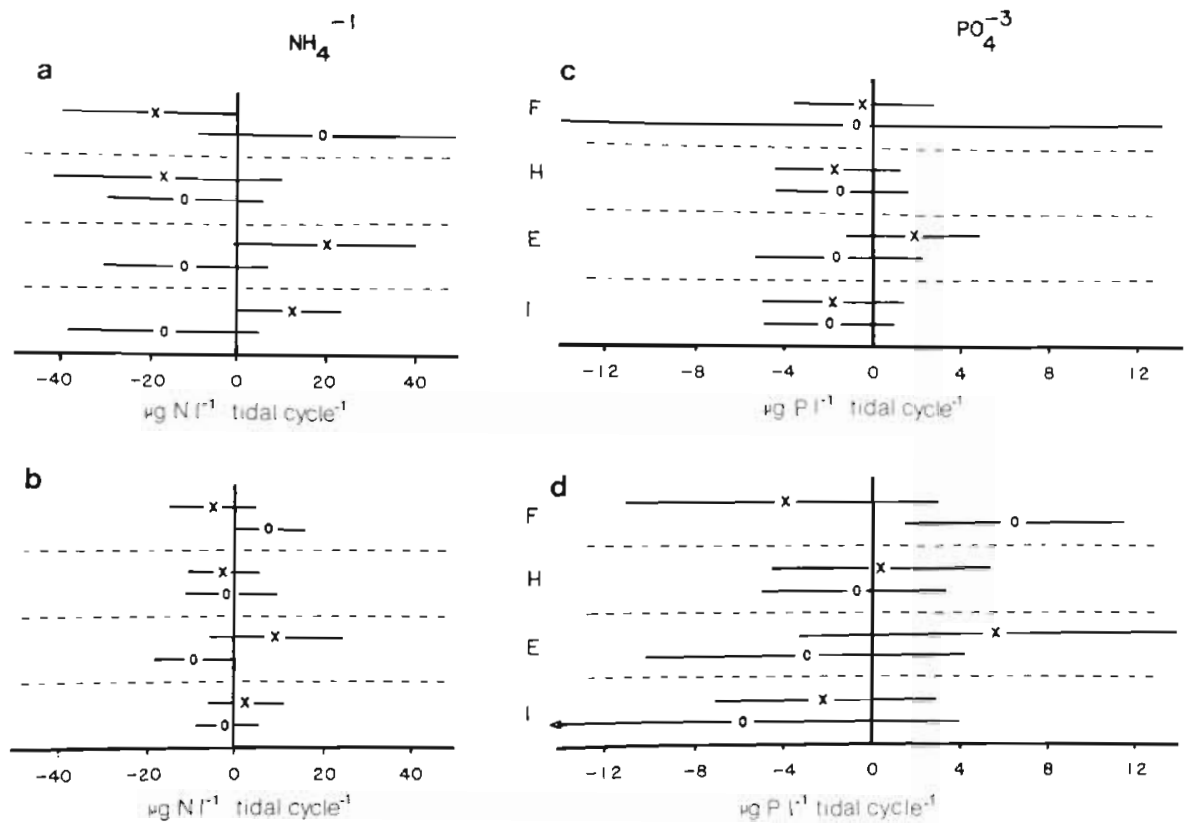

Fig. 2. Mean nutrient exchange ( $\left.\mu \mathrm{g}^{-1}\right)$ per tidal cycle as a function of season, depth within the water column, and tidal parcel. (a) $\mathrm{NH}_{4}{ }^{+1}$, winter; (b) $\mathrm{NH}_{4}{ }^{+1}$, summer; (c) $\mathrm{PO}_{4}{ }^{-3}$, winter; (d) $\mathrm{PO}_{4}{ }^{-3}$, summer. x Depth 1 (sediment-water interface); 0 Depth 2 (water

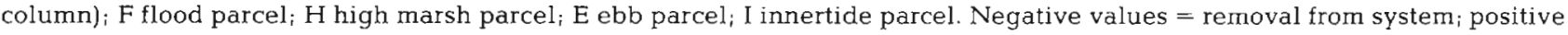
values $=$ insertion into system

$$
\mathrm{NO}_{2}^{-1}
$$

a

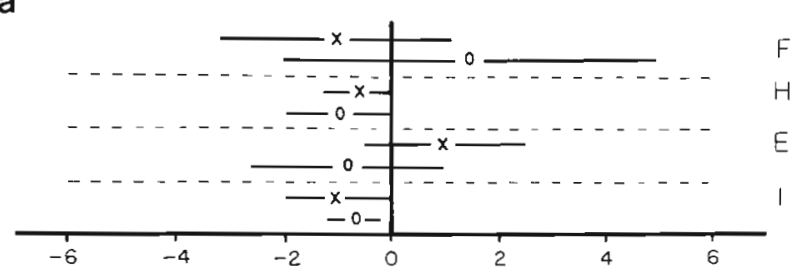

b

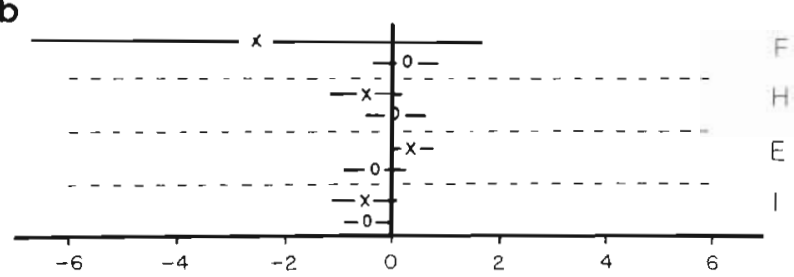

c

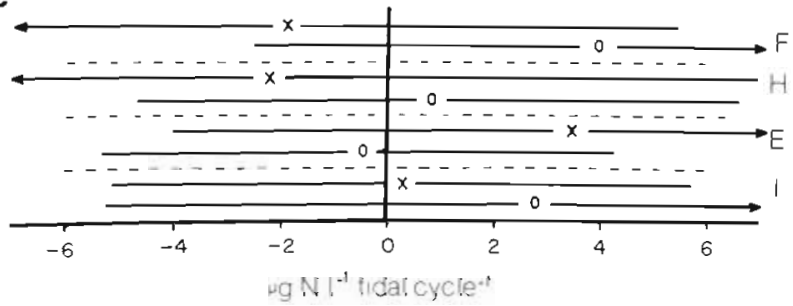

Fig. 3. Mean nutrient exchange $\left(\mu \mathrm{g}^{-1}\right)$ per tidal cycle for $\mathrm{NO}_{2}{ }^{-1}$ as a function of season, depth within the water column, and tidal parcel. (a) $\mathrm{NO}_{2}^{-1}$, winter; (b) $\mathrm{NO}_{2}^{-1}$, summer; (c) $\mathrm{NO}_{2}{ }^{-1}$, fall. $x$ Depth 1 (sediment-water interface); 0 Depth 2 (water column); F flood parcel; $H$ high marsh parcel; $E$ ebb parcel; I innertide parcel. Negative values = removal from system; positive values $=$ insertion into system removal of this constituent from the tidal water especially in Depth 1 of the flood parcel (summer period). Only in Depth 2 of the flood and ebb parcels during the winter is there an insertion of nitrite into the tidal water. During the fall there is a release of nitrite into the tidal water from the water column (Depth 2), within the flood, high marsh, and innertide parcels (Fig. 3c).

Removal of nitrate from the tidal water near the sediment-water interface (Depth 1) decreases as a function of time over the tidal cycle (flood parcel $\rightarrow$ high marsh parcel $\rightarrow$ ebb parcel) (Fig. 4a, b). Negligible exchange occurs within the ebb and innertide parcel (Depth 1) during the summer. While within the water column (Depth 2), nitrate is either removed from the tidal water or there is negligible exchange. Nitrate may be released into the flood parcel (Depth 2) during the winter (Fig. 4a).

Removal of dissolved organic phosphorus from the inundating water was observed during the winter from the high marsh, and innertide parcels, whereas a net release of this constituent into the ebb and flood parcel was evident (Table 1). A similar trend was observed during the summer but in this case there is a release of DOP into the innertide water parcel. A removal of DON from the tidal water was found within the high marsh, ebb, and innertide parcels, and a release of this constituent into the flood parcel during both the $w$ and $s$ time periods.

There was a removal of particulate phosphorus from the flood, high marsh and innertide parcels, with a 

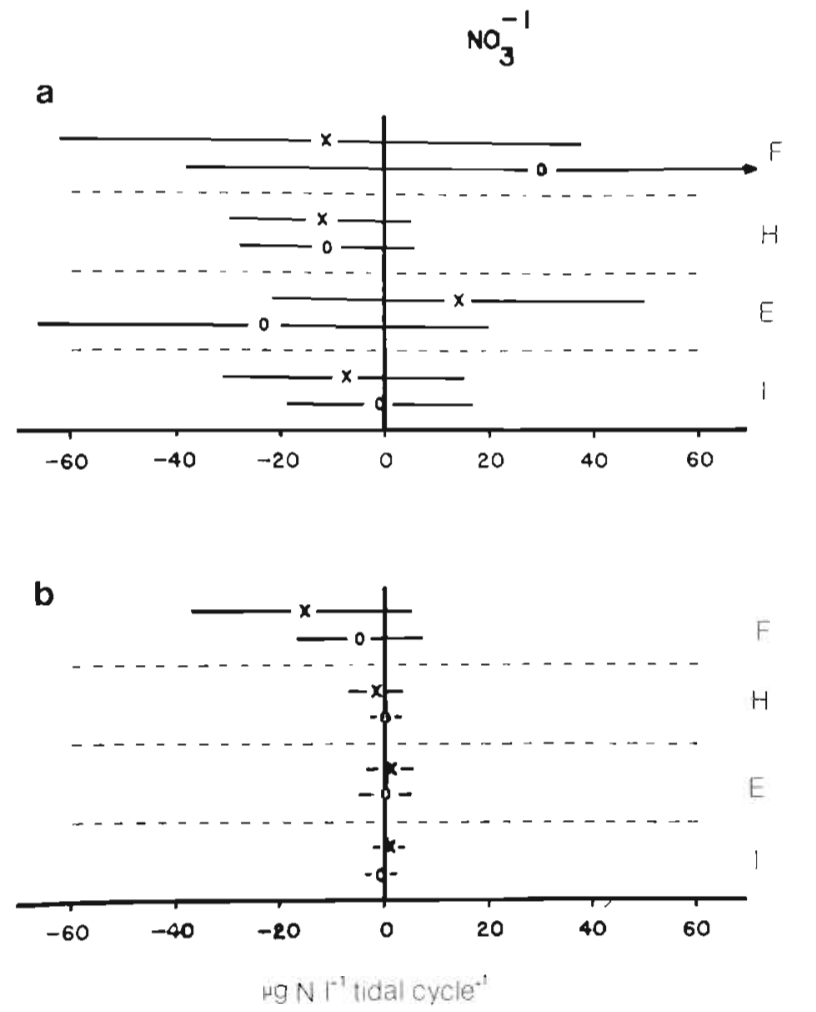

Fig. 4. Mean nutrient exchange $\left(\mu \mathrm{g}^{-1}\right)$ per tidal cycle for $\mathrm{NO}_{3}{ }^{-1}$ as a function of season, depth within the water column, and tidal parcel. (a) $\mathrm{NO}_{3}^{-1}$, winter; (b) $\mathrm{NO}_{3}{ }^{-1}$, summer. $\mathrm{x}$ Depth 1 (sediment-water interface); 0 Depth 2 (water column); F flood parcel; $\mathrm{H}$ high marsh parcel; E ebb parcel; I innertide parcel. Negative values = removal from system; positive values $=$ insertion into system

release of this constituent into the ebb parcel during both the winter and summer (Table 1). Within each season the largest amounts of material were removed from the flood parcel. Particulate nitrogen was removed from the tidal water in all the tidal parcels during the summer and from the flood, high marsh and innertide parcels during the winter. Only within the ebb parcel during the winter was there any release of this material. The largest removal of particulate nitrogen from the tidal water occurred in the flood and high marsh parcels regardless of time period.
The results from the chamber experiments are listed in Table 2. During the summer period (sample dates June 29, July 13, August 22) there was a release of both ammonium and orthophosphate into the water column, while during early summer and fall (June 3 , October 2) there was an uptake of these constituents. The sediment subsystem acted as a source or sink for ammonia and orthophosphate with respect to the water column. Throughout the chamber study period nitrite and nitrate were always removed from the water column by waterborne organisms, the sediment system having only a small effect on the nutrient concentrations within the chambers.

\section{DISCUSSION}

The results of this study indicate that the factors which control the nitrogen and phosphorus composition of tidal water inundating the vegetated mesohaline marsh are both chemical and physical in nature. These factors differ as a function of location on the marsh, time over the tidal cycle, and depth within the water column.

The nutrient exchange data for ammonium illustrates this point well, since both sediment and water column processes control the level of ammonium within the tidal water, resulting in a high degree of cycling within the system. Ammonium is released into the flooding water on the low marsh from within the water column. This is substantiated by (1) the nutrient exchange data which indicated this constituent was released into the water column (Depth 2) of the flood parcel during both the winter and summer (Fig. 2a, b), and (2) the results from the chamber experiments which show that ammonium can be released into the tidal water from the water column during the summer (Table 2). If this occurs, ammonium is utilized immediately by the sediment system within the low marsh (Depth 1, Fig. 2a, b) or transported to the high marsh where it is subsequently removed. It is difficult to determine if water column or sediment processes are responsible for the removal of ammonium from the

Table 1. Mean nutrient exchange $\left(\mu \mathrm{g}^{-1}\right)$ per tidal cycle as a function of parcel and season. $\mathrm{w}=$ winter; $\mathrm{s}=$ summer; - removal from tidal parcel ${ }_{i}+$ insertion into tidal parcel

\begin{tabular}{|c|c|c|c|c|c|c|c|c|}
\hline \multirow[t]{2}{*}{ Parcel } & \multicolumn{2}{|c|}{$\begin{array}{c}\text { Dissolved } \\
\text { organic phosphorus }\end{array}$} & \multicolumn{2}{|c|}{$\begin{array}{c}\text { Dissolved } \\
\text { organic nitrogen }\end{array}$} & \multicolumn{2}{|c|}{$\begin{array}{l}\text { Particulate } \\
\text { phosphorus }\end{array}$} & \multicolumn{2}{|c|}{$\begin{array}{l}\text { Particulate } \\
\text { nitrogen }\end{array}$} \\
\hline & $w$ & $\mathrm{~s}$ & $w$ & $\mathrm{~s}$ & $w$ & $\mathrm{~s}$ & $w$ & s \\
\hline Flood & 4.95 & -2.4 & 8.9 & 27.5 & -58.0 & -158.6 & -237.0 & -659 \\
\hline High marsh & -3.65 & -14.7 & -51.4 & -51.3 & -1.97 & -72.5 & -159.0 & -494.0 \\
\hline$E b b$ & 1.88 & 3.49 & -14.9 & -76.8 & 5.75 & 18.8 & 97.0 & -221.0 \\
\hline Innertide & -1.25 & 0.75 & -61.0 & -27.0 & -9.3 & -99.7 & -44.0 & -147.0 \\
\hline
\end{tabular}


Table 2. Nutrient fluxes $\left(\mu \mathrm{g} \mathrm{m}^{-2}\right.$ tidal $\left.\mathrm{cycle}^{-1}\right)$ for chamber experiments. Control = exchange with water column; Sed $=$ exchange with sediment substrate $;$ - removal from system; + release into system

\begin{tabular}{|c|c|c|c|c|c|c|c|c|c|c|c|c|}
\hline Date & Control & $\begin{array}{l}\mathrm{NH}_{4} \\
\text { Sed }\end{array}$ & Sed & Control & $\begin{array}{c}\mathrm{PO}_{4}^{-3} \\
\mathrm{Sed}\end{array}$ & Sed & Control & $\begin{array}{c}\mathrm{NO}_{2}^{-1} \\
\text { Sed }\end{array}$ & Sed & Control & $\begin{array}{l}\mathrm{NO}_{3}{ }^{-1} \\
\text { Sed }\end{array}$ & Sed \\
\hline $6 / 3$ & -4125 & -5033 & -2755 & -1469 & +1199 & +198 & -1722 & +600 & +462 & -1001 & +22 & +22 \\
\hline $6 / 29$ & +1733 & -2316 & -2596 & +528 & -1095 & -3751 & -974 & 00 & 00 & -24365 & 00 & 00 \\
\hline $7 / 13$ & - & - & - & +1683 & -7178 & +627 & -743 & 00 & 00 & -6710 & 00 & 00 \\
\hline $8 / 22$ & +302 & +29865 & -9295 & +1342 & +5341 & -776 & -1502 & 00 & 00 & -45155 & 00 & 00 \\
\hline $10 / 2$ & -6710 & +11055 & -18590 & - & - & - & -1502 & +1496 & 00 & & - & - \\
\hline
\end{tabular}

tidal water over the high marsh since the means of nutrient exchange (Depth 1, Depth 2; Fig. 2a, b) are not statistically different. The sediment system is probably responsible for the removal of ammonium from the water column since the sediment surface is covered with a thick mat of Spartina alterniflora detritus. It has been shown by Ustach (1969) and Heywood (1977) that microflora decomposing this material will utilize nitrogen and phosphorus in order to hasten the degradation process.

Throughout the year ammonium is released into the ebb parcel from the sediment system, this material utilized immediately within the water column (Fig. 2a, b). Within the innertide parcel there is also a release of ammonium from the sediment to the tidal water (Depth 1 , summer), this in part utilized within the water column (Depth 2) or removed from the marsh surface. The release of ammonium from the low marsh sediments into the ebb and innertide parcels during the summer period is assosiated with the low oxygen content of the estuarine water coupled with the redox layer within the sediment approaching the sediment-water interface (own unpubl. data). Both these factors enhance the diffusion of $\mathrm{NH}_{4}^{+1}$ from the sediment into the tidal water. This is substantiated by the results from the low marsh sediment experimental chambers which indicate that the sediment system can release $\mathrm{NH}_{4}{ }^{+1}$ into the water column, and the high values of ammonium in the interstitial water of the sediment substrate (ca. $4 \mathrm{mg} \mathrm{N}^{-1}$ ). It appears that even during the winter, ammonium was released into the ebb water parcel, via diffusion. The results from the MANOVA analysis indicate that there is a difference between the nutrient exchange in Depths 1 and 2 of the flood, ebb, and innertide parcels $(p<.1)$. This implies there is a difference in nutrient activity within Depths 1 and 2 as a function of parcel.

As with ammonium, $\mathrm{PO}_{4}^{-3}$ is rapidly cycled within the marsh system, none escaping to the contiguous estuary. In general the means for $\mathrm{PO}_{4}{ }^{-3}$ activity (Fig. $2 \mathrm{c}$, d) as a function of depth and parcel follow the same trends as $\mathrm{NH}_{4}{ }^{+1}$. Most of the nutrient exchange means as a function of depth within each parcel are not statistically different since the means are small and the standard deviation relatively large. In summer there was a slight net release of orthophosphate into the water column of the flood parcel (Depth 2; Fig. 2 d); this was also observed with the chamber experiments for this period (Table 2). This material is either removed by low marsh sediments (Depth 1, Fig. 2d) or as tidal water resides on the high marsh. Later in the tidal cycle there is diffusion of $\mathrm{PO}_{4}{ }^{-3}$ from sediment of the low marsh into tidal water (Depth 1) of the ebb parcel, particularly during summer (Fig. 2 d). This assertion is supported by the high concentration of orthophosphate within the sediment column (approx. $4 \mathrm{mg} \mathrm{P} \mathrm{l}^{-1}$ unpubl. data) and the chamber experiments which indicate that this constituent can be released from the sediment (Table 2). The $\mathrm{PO}_{4}{ }^{-3}$ released from the low marsh sediments during the ebb tide is utilized within the water column of the ebb parcel. The chamber studies during the late spring showed that the water column can be responsible for an uptake of $\mathrm{PO}_{4}{ }^{-3}$. It must be stressed that the experimental chamber data indicates that the sediment substrate can release and utilize both orthophosphate and ammonium, indicating that the low marsh sediment is patchy with respect to function. Some of the chambers probably were placed over sediment which contained patches of microflora (algae); this substrate removed the above constituents, while chambers placed on sediment containing smaller numbers of microorganisms acted as a nutrient source via diffusion.

Nitrite was either utilized by the vegetated marsh or there was negligible activity during the summer (Fig. 3b), removal occurring for most of the tidal cycle during the winter (Fig. 3a). In winter, biological processes do not proceed fast enough to remove all of this constituent from the water in the flood parcel, some removal and insertion into the tidal water occurring later in the tidal cycle. During summer, increased biological activity accounts for complete utilization of this constituent in the flood parcel, only a small amount being transported onto the high marsh (Fig. $3 b)$. The relatively large removal of nitrite from the flood parcel (Depth 1, summer) may imply that nitrite 
is reduced within the sediment substrate via denitrification. This process has been shown to be active in all the vegetated zones of a salt marsh (Kaplan et al., 1979). During both winter and summer, nitrite can be removed from the water column (Depth 2, Fig. 3a, b). Water column uptake is verified by the results from all chamber experiments conducted on the low marsh (Table 2). These results indicate that as water height over the sediment increases (flood to high slack water) there is a shift in $\mathrm{NO}_{2}{ }^{-1}$ utilization. When water depth is low and sediment surface to water volume is high, nitrite may be used both for denitrification within the sediment and as a nutrient within the water column, but as the water depth increases, most of the nitrite within the tidal water is utilized within the water column. During fall, large releases of nitrite into the water column (Depth 2), was observed in 3 of the 4 tidal parcels, while both uptake and release with respect to Depth 1 was observed. Since Spartina alterniflora is inundated to the greatest depth within the innertide parcel and is also inundated during all other tidal phases, it seems plausible that these macrophytes play a significant role in the release of this constituent into the tidal water. There are very few statistically significant differences in the nutrient activity of nitrite as a function of season, depth, or parcel. This is attributed to the low level of nutrient exchange.

Nitrate was removed from the inundating water throughout most of the year, regardless of water parcel (Fig. $4 \mathrm{a}, \mathrm{b}$ ). During summer most of the uptake of this constituent occurred within the flood parcel (Fig. 4b). There is not a significant difference in the nutrient activity between Depth 1 and Depth 2 of the flood parcel (summer), even though there was a relatively large uptake at the sediment-water interface. This implies that denitrification within the sediment system may be responsible for the observed removal of this constituent along with water column processes. The chamber experiments (Table 2) indicate that water column events are very effective at removing $\mathrm{NO}_{3}{ }^{-1}$ from the tidal water. Nitrate is not found in the other water parcels during the later summer months since biological activity is rapid enough to remove most of this constituent from the flooding water early in the tidal cycle. During winter nitrate is utilized within Depths 1 and 2 of most of the tidal parcels. During this period nutrient exchange occurs both at the sedimentwater interface and within the water column throughout the tidal cycle. As with nitrite it appears that if the water-volume to sediment-area ratio is large enough then water column processes will account for most of the nitrate removal on an areal basis.

The dissolved organic species of nitrogen and phosphorus show similar exchange characteristics in that there is always a removal of these constituents from the high marsh parcel and either release or uptake of these constituents with respect to the flood, ebb or innertide water parcels depending on season or constituent (Table 1). The release of dissolved organic species into the tidal water is probably associated with invertebrate excretion (Axelrad, 1974) while the removal of these constituents from the tidal water over the low and high marsh may be associated with the decomposition of detrital material. Particulate nitrogen and phosphorus are always removed from the tidal water from the flood, high marsh, and innertide parcels, while a release of these constituents into the ebb parcel is evident (Table 1). Regardless of season, the greatest amount of material is deposited on the low marsh from the flood water parcel (Table 1). This is related to the sediment trapping effect of Spartina alterniflora stems (Gleason et al., 1979) and the release of bedload material as inundating water slows near high slack water. Particulates not removed from the tidal water over the low marsh (flood and innertide parcel) are removed from the water over the high marsh. As the water leaves the low marsh on the ebb tide (ebb parcel) some particulates are resuspended into the tidal water either due to wave scouring of the sediment surface or increased tidal water velocity. For particulate nitrogen the later process is very important since the marsh is a net exporter of particulate nitrogen during the colder months (Wolaver, 1983a, b). In this analysis, PN is not exported during the winter time period since it incorporates the late spring in which there was a large import of PN onto the marsh surface.

\section{CONCLUSIONS}

The results from this study indicate that the processing of nitrogen and phosphorus within the vegetated mesohaline marsh is a function of depth within the water column, location on the marsh, and time over the tidal cycle.

(1) Ammonium and orthophosphate are removed from the tidal water by the sediment substrate on the low and high marsh during the flood tide. Later in the tidal cycle these constituents are released into the water column from the low marsh sediments. The release of these nutrients is attributed to sediment diffusion. There is a release of ammonium and orthophosphate, probably via waterborne organisms, into the tidal water over the low marsh (flood tide during summer), while these constituents are removed from the tidal water as it resides on the high and low marsh later in the tidal cycle. These results indicate a high degree of internal cycling between sediment substrate and water column.

(2) Nitrate and nitrite are removed from the tidal 
water during winter and summer, while there is a release of nitrite into the tidal water during fall. The latter is attributed to the senescence of marsh macrophytes. These constituents are utilized by both the sediment substrate and the water column within the low marsh during the flood tide, whereas near high slack water, water column events are responsible for most of the removal of these constituents. It appears there is a shift in utilization of nitrate and nitrite from the sediment and water column to the water column depending on the height of tidal water. This is attributed to an increase in the water volume to sedimentsurface ratio which occurs as tidal height over the low marsh sediments increases.

(3) Dissolved organic nitrogen and phosphorus are both released and removed from the tidal water over the low marsh depending on season and time over the tidal cycle. There is a removal of DON and DOP from the water as it resides on the high marsh; this is probably related to the metabolic requirements of the microflora and microfauna utilizing the large load of detritus on the marsh surface.

(4) Particulate nitrogen and phosphorus are removed from the tidal water over both the low and high marsh on the flood tide, this material being either trapped by Spartina alterniflora stems or dropped as bedload near high slack water. On the ebb tide some of this material is resuspended as the water leaves the low marsh.

\section{LITERATURE CITED}

Armentano, T. V., Woodwell, G. M. (1975). Sedimentation rates in a Long Island marsh determined by $\mathrm{Pb}-210$ dating. Limnol. Oceanogr. 20: 452-456

Aurand, D., Daiber, F. C. (1973). Nitrate and nitrite in the surface waters of two Delaware salt marshes. Chesapeake Sci. 14: 105-111

Axelrad, D. M. (1974). Nutrient flux through the salt marsh ecosystem. Ph. D. thesis, College of William and Mary

Gardner, L. R. (1975). Runoff from an intertidal marsh during tidal exposure recession curves and chemical characteristics. Limnol. Oceanogr. 20: 81-89

Gleason, M. L, Elmer, D., Pien, N., Fisher, J. (1979). Effects of stem density upon sediment retention by salt marsh cordgrass, S. alterniflora Loisel. Estuary 2: 271-173

Hanson, R. B. (1977a). Nitrogen fixation (acetylene reduction) in a salt marsh amended with sewage sludge and organic carbon and nitrogen compounds. Appl. environ. Microbiol. 33: 346-852

Hanson, B. (1977b). Comparison of nitrogen fixation activity in tall and short Spartina alterniflora salt marsh soils. Appl. environ. Microbiol. 33: 596-602
Heinle, D. R., Flemer, D. A. (1976). Flows of materials between poorly flooded tidal marshes and an estuary. Mar. Biol. 35: 359-373

Heywood, M. A. (1977). Enriched decay of two marsh plants. Masters thesis, University of Virginia

Kaplan, W., Valiela, I., Teal, J. M. (1979). Denitrification in a salt marsh ecosystem. Limnol. Oceanogr. 10 (2): 167-172

Patrick, W. H., Khalid, R. A. (1974). Phosphate release and sorption by soils sediments: effect of aerobic and anaerobic conditions. Science, N. Y. 186: 53-55

Pomeroy, L. K. (1963). Experimental studies of the turnover of phosphate in marine environments. In: Schultz, V., Klement, A. W., Jr. (eds.) Radioecology. Reinhold, New York, p. $163-166$

Pomeroy, L. R., Smith, F. E., Grant, C. M. (1965). The exchange of phosphate between estuarine water and sediments. Limnol. Oceanogr. 10: 176-172

Reimold, R. J. (1972). The movement of phosphorus through the salt marsh cord grass Spartina alternifloras Loisel. Limnol. Oceanogr. 17: 606-611

Sherr, B. F., Payne, W. J. (1977). Effect of the Spartina alterniflora root rhizome system on salt marsh soil denitrifying bacteria. Appl environ. Microbiol. 35: 724-729

Stephens, G. C. (1963). Uptake of organic material by aquatic invertebrates. II. Accumulation of amino acids by the bamboo worm, Clymenella torquata. Comp. Biochem. Physiol. 10: 191-202

Stephens, G. C. (1964). Uptake of organic material by aquatic invertebrates. III. Uptake of glycine by brackish water annelids. Biol. Bull. mar biol. Lab., Woods Hole 126: $150-162$

Stephens, G. C. (1967). Dissolved organic material as a nutritional source for marine and estuarine invertebrates. In: Lauff, G. H. (ed.) Estuaries. Publs Am. Ass. Advmt Sci., Washington

Ustach, J. F. (1969). The decomposition of Spartina alterniflora. Masters thesis, N.C. State University at Raleigh

Valiela, I., Teal, J. M., Volkman, S., Shafer, D., Carpenter, E. J. (1978). Nutrient and particulate fluxes in salt marsh ecosystems: tidal exchanges inputs by precipitation and groundwater. Limnol. Oceanogr. 23: 798-812

Whitney, D. E., Woodwell, G. M., Howarth, R. W. (1975). Nitrogen fixation in Flax Pond, a Long Island salt marsh. Limnol. Oceanogr. 4: 640-643

Wolaver, T G. (1983a). Nitrogen and phosphorus exchange between a mesohaline vegetated marsh and the surrounding estuary in the lower Chesapeake Bay. Estuar coast. Shelf Sci. (in press)

Wolaver, T. G. (1983b). The role of tall and medium Spartina alterniflora zones in the processing of nutrients in tidal water. Estuar. coast. Shelf Sci. (in press)

Woodwell, G. M., Whitney, D. E. (1977). Flax Pond ecosystem study: exchanges of phosphorus between a salt marsh and the coastal waters of Long Island Sound. Mar. Biol. 41: 1-6

Woodwell, G. M., Hall, C. A. S., Whitney, D. E., Hougnton, R. A. (1979). The Flax Pond ecosystem study: exchanges of inorganic nitrogen between an estuarine marsh and Long Island Sound. Ecology 60 (4): 695-702 